\title{
A significação das medidas socioeducativas para as famílias de adolescentes privados de liberdade
}

\author{
Luana Alves de Soura - Universidade de Brasilia, Brasília/ DF, Brasil \\ Liana Fortunato Costa - Universidade de Brasilia, Brasilia/ DF, Brasil
}

\begin{abstract}
Resumo
O presente estudo objetiva apresentar o significado que as famílias de adolescentes privados de liberdade atribuem à medida socioeducativa de internação e às medidas socioeducativas cumpridas anteriormente à internação. A partir de uma abordagem qualitativa, foi realizado estudo de caso de três famílias que possuem filhos em cumprimento de internação no Centro de Integração de Adolescentes de Planaltina (CIAP). Os instrumentais utilizados foram a visita domiciliar e as entrevistas semiestruturadas, e, para a análise e a interpretação dos dados, foi utilizada a análise de conteúdo. A pesquisa evidencia que a internação, apesar de restringir a liberdade dos adolescentes, é significada pelas famílias como a única medida socioeducativa que consegue garantir a proteção de seus filhos, em contraponto às demais medidas socioeducativas.
\end{abstract}

Palavras-chave: Família, Adolescente infrator, Medidas socioeducativas.

The significance of socio-educational measures for families of adolescents in deprived of freedom

\begin{abstract}
The present study aims at presenting the meaning that families of adolescents deprived of freedom attribute to the socioeducative measure of internment and to the socio-educative measures served prior to institutionalization. As from a qualitative approach, a case study of three families who have sons institutionalized at the Adolescents Integration Center of Planaltina was performed. The instruments used were home visits and semi-structured interviews and, for the analysis and interpretation of data, the content analysis. The research shows that institutionalization, in spite of restricting freedom of the adolescents, is considered by the families as the only socio-educative measure that guarantees the protection of their sons, in opposite to the other socio-educative measures.

Keywords: Family, Transgressor adolescent, Socio-educative measures.
\end{abstract}

\section{La importancia de las medidas educativas para las familias de los adolescentes encarcelados}

\begin{abstract}
Resumen
El presente estudio tiene por objetivo presentar el significado que las familias de los adolescentes encarcelados atribuyen a las medidas socioeducativas cumplidas anteriormente al encarcelamiento. Desde un enfoque cualitativo se realizó un estudio de caso de tres familias que tenían hijos encarcelados en el Centro de Integración de Adolescentes de Planaltina (CIAP). Se utilizaron la visita domiciliar y a las entrevistas semiestructuradas, y para el análisis y la interpretación de los datos se utilizó el análisis de contenido. La investigación evidencia que el encarcelamiento a pesar de que limita la libertad de los adolescentes, es representado por las familias como la única medida socioeducativa que puede garantizar la protección de sus hijos, a diferencia a las demás medidas socioeducativas.

Palabras clave: Familia, Adolescente delincuente, Medidas socioeducativas.
\end{abstract}

O presente artigo é fruto de pesquisa de mestrado acadêmico cujo objetivo foi investigar qual o significado que os adolescentes e seus familiares atribuem à medida socioeducativa de internação e às medidas socioeducativas cumpridas anteriormente à internação. Neste texto, preservou-se o recorte que trata apenas da significação das medidas socioeducativas para as famílias dos adolescentes.

\section{A medida de proteção e socioeducativa}

Em relação à proteção de crianças e adolescentes, o paradigma da Doutrina da Proteção Integral, considera-os como sujeitos de direitos em relação ao mundo adulto; são sujeitos de direitos em suas relações com a família, a sociedade e o Estado (Conceição, 2010; Machado, 2003). Nas palavras de Machado (2003), tal doutrina é norteada pela noção de que

[...] crianças e adolescentes são seres bumanos que se encontram numa situação fática peculiar, qual seja, a

Disponivel em monv.scielo.br de pessoas em fase de desenvolvimento físico, psíquico, emocional, em processo de desenvolvimento de sua potencialidade bumana adulta; e que essa peculiar condição merece respeito e para tal há de se compreender que os direitos fundamentais de crianças e adolescentes são especiais em relação ao direito dos adultos (há necessidade de direitos essenciais especiais e de estruturação diversa desses direitos) (Machado, 2003, p. 50).

Ademais, tais direitos são prioritários. Crianças e adolescentes devem receber da sociedade e do Estado um único e igualitário regime de direitos fundamentais, livres de tratamento discriminatório ou opressivo, ou seja, a Doutrina da Proteção Integral aponta como postura "irregular" não a criança ou o adolescente, como entendia a Doutrina da Situação Irregular, mas todo e qualquer agente violador, inclusive o próprio poder público (Veronese \& Luz, 2006). 
É a Doutrina da Proteção Integral que irá nortear a Constituição Brasileira de 1988 (Brasil, 1988) e, consequentemente, o Estatuto da Criança e do Adolescente (ECA, 1990). O artigo 227 da Constituição Federal assegura uma série de direitos à criança e ao adolescente, estabelecendo que esses direitos devem ser assegurados pela sociedade, pelos pais e pelo Estado. O ECA considera criança os sujeitos que se encontram na faixa etária de 0 a 12 anos incompletos e adolescente os sujeitos que possuem de 12 a 18 anos incompletos. Um dos grandes avanços trazidos pelo ECA, conforme expõe Garcia (1999), é que este inaugura uma nova forma de gerir os direitos da criança e do adolescente, pautada no Sistema de Garantia de Direitos (SGD), que é definido por Wanderlino (1999) como um verdadeiro sistema estratégico, jurídico, político e institucional que irá se integrar e se articular na garantia do acesso de crianças e adolescentes aos serviços e programas necessários, assim como o acesso à Justiça, por exemplo.

O ECA estabelece, em seu artigo 98, que as medidas de proteção serão aplicadas sempre que houver violação dos direitos estabelecidos no próprio ECA por "ação ou omissão da sociedade ou do Estado", ou "por falta, omissão ou abuso dos pais ou responsável". Mas não somente omissões dessa natureza podem motivar a aplicação das medidas de proteção. O inciso III do artigo 98 também aponta o próprio comportamento da criança ou adolescente como causa de aplicação de medidas protetivas. Em relação aos direitos que devem ser assegurados às crianças e adolescentes, pode-se dizer que estão todos previstos na legislação protetiva, como vida, saúde, educação, lazer, convívio familiar etc. Assim, as medidas protetivas que visam assegurar tais direitos estão postas no artigo 101 do ECA. Uma questão importante para este estudo é o fato de que as medidas protetivas, conforme já mencionado, podem ser aplicadas em razão da conduta do adolescente. Dessa forma, quando este comete ato infracional e é aplicada medida socioeducativa, esta poder ser entendida como uma espécie de medida de proteção, embora seja voltada a situações relacionadas ao cometimento de ato infracional. Quando uma criança (até 12 anos incompletos) comete ato infracional, não pode ser aplicada medida socioeducativa, mas apenas medida protetiva.

As medidas socioeducativas são aplicadas quando verificadas situações nas quais o comportamento do adolescente assume uma tipologia de crime ou contravenção penal, conforme previsto no artigo 103 do Estatuto. É de se grafar que as medidas socioeducativas não têm natureza de pena, de punição. Em consonância com o artigo 112 do ECA, as medidas socioeducativas que poderão ser aplicadas aos adolescentes são: Advertência; Obrigação de reparar o dano; Prestação de Serviços à Comunidade; Liberdade Assistida; Semiliberdade e Internação.

\section{A compreensão sistêmica da familia}

Para a compreensão das relações familiares, o texto baseia-se na perspectiva sistêmica defendida por Esteves de Vasconcellos (2002), ou seja, a compreensão dos fatos analisados levará em consideração os três pilares do novo paradigma da ciência, quais sejam, o pressuposto da complexidade, pois o fenômeno estudado é compreendido dentro de um contexto; o pressuposto da instabilidade, já que o sistema sofre alterações no decorrer do tempo; e o pressuposto $\mathrm{da}$ intersubjetividade, uma vez que também consideramos a percepção dos adolescentes sujeitos da pesquisa, considerando, assim, outras descrições do fenômeno. Compreende-se a família como um sistema aberto em transformação, que opera dentro de contextos sociais específicos, constituído por três componentes, conforme aponta Minuchin (1982). Primeiro, a estrutura da família é de um sistema sociocultural aberto em transformação. Segundo, a familia passa por um desenvolvimento, atravessando certo número de estágios, que requer reestruturação. Terceiro, a familia se adapta a circunstâncias modificadas, de maneira a manter a continuidade e a intensificar o crescimento psicossocial de cada membro. A existência de um adolescente em conflito com a lei significa um aviso de que existem problemas no sistema, pois o adolescente é intensamente afetado pelo contexto familiar e também afeta o contexto do qual faz parte (Bulaccio, 1992; Fishman, 1988). Ressalta-se ainda que a relação adolescente-família é também afetada pelo contexto social ao qual está inserida, bem como a afeta. Nesse sentido, Segond (1992) coloca que sendo a famillia um subsistema dentro da sociedade, "[...] esta mesma exerce sobre a familia, direta ou indiretamente, violências que não são simplesmente erros, mas que também podem ser quase institucionalizadas" (p. 442-443). Ou seja, é fundamental o olhar sobre a realidade social na qual os adolescentes em conflito com a lei e suas famílias vivem (Sales, 2007; Volpi, 2001).

Portanto, para além da discussão sobre adolescência e família, há de se considerar essa relação num contexto mais amplo, ao qual estão inseridas as instituições, as questões sociais, por exemplo. No caso da medida socioeducativa de internação, quando o adolescente está privado de sua liberdade, ainda que de forma precária, ele tem acesso à escola, à saúde, às atividades profissionalizantes, sem falar da participação das famílias, que ocorre por meio das visitas semanais. 
Será necessário restringir o direito à liberdade dos adolescentes para conseguir garantir um mínimo de proteção? Castro e Guareschi (2007) colocam que a pobreza e as carências materiais podem ser vistas como condição prévia de vulnerabilidade que leva o adolescente a um lugar de exclusão. Para esses adolescentes em conflito com a lei, as situações de violência fazem parte de seu cotidiano, o que os torna não só vítimas, mas também causadores dessa violência. Desse modo, particularmente para aqueles jovens provenientes das camadas mais pobres, "a violência pode ser pensada como uma forma de resistir às injustiças sociais e ascender ao mundo do consumo" (p. 4). Tornam-se outsiders não só por violarem as regras impostas, mas por também não serem inseridos nos padrões estabelecidos socialmente. Portanto, neste trabalho, enfoca-se a questão das medidas socioeducativas pela ótica das familias, como elas as significam, como diferenciam a internação das demais medidas socioeducativas, como participam da execução das medidas socioeducativas dos filhos.

\section{Contexto}

\section{Método}

A pesquisa foi realizada no Centro de Integração de Adolescentes de Planaltina (CIAP), uma das unidades de execução da medida socioeducativa de internação estrita (medida estabelecida por tempo indeterminado e não excedente a 3 anos), localizado em uma cidade satélite de Brasília, DF.

\section{Participantes}

Os sujeitos da pesquisa são três famílias de adolescentes que estão em cumprimento da medida socioeducativa de internação estrita e que já cumpriram outras medidas socioeducativas anteriormente. A Tabela 1 apresenta de modo sucinto os participantes da pesquisa, aos quais foram dados nomes fictícios. Alan tem 17 anos, seu ato infracional foi roubo e está internado há 1 ano e 4 meses. Breno tem 17 anos, seu ato infracional foi porte de arma e está internado há 10 meses. Carlos tem 19 anos, seu ato infracional foi homicídio e está internado há 2 anos.

Tabela 1. Famílias entrevistadas

\begin{tabular}{|c|c|c|c|c|c|c|}
\hline $\mathrm{N}^{\mathrm{o}}$ & $\begin{array}{c}\text { Adolescente/ Familiar } \\
\text { entrevistado }\end{array}$ & $\begin{array}{l}\text { Familiares que } \\
\text { residem na } \\
\text { mesma casa }\end{array}$ & Profissão dos pais & $\begin{array}{c}\text { Situação } \\
\text { conjugal dos } \\
\text { pais }\end{array}$ & $\begin{array}{l}\text { Situação da } \\
\text { moradia }\end{array}$ & $\begin{array}{l}\text { Renda } \\
\text { familiar }\end{array}$ \\
\hline 1 & Alan / Genitora & $\begin{array}{l}\text { Mãe, } 1 \text { irmã, } 1 \\
\text { irmão }\end{array}$ & $\begin{array}{l}\text { Genitora: do lar } \\
\text { Genitor: agricultor }\end{array}$ & Separados & Casa própria & $\mathrm{R} \$ 510,00$ \\
\hline 2 & Breno/Genitora e irmãos & $\begin{array}{l}\text { Mãe, pai, } 1 \text { irmã } \\
\text { e } 1 \text { irmão }\end{array}$ & $\begin{array}{l}\text { Genitora: doméstica } \\
\text { Genitor: pedreiro }\end{array}$ & Casados & $\begin{array}{l}\text { Casa } \\
\text { alugada }\end{array}$ & $\begin{array}{c}\mathrm{R} \$ \\
1.500,00\end{array}$ \\
\hline 3 & Carlos/Genitora & $\begin{array}{l}\text { Mãe, } 1 \text { irmã, } 2 \\
\text { sobrinhas }\end{array}$ & $\begin{array}{l}\text { Genitora: doméstica } \\
\text { Genitor: não } \\
\text { informado }\end{array}$ & Separados & $\begin{array}{l}\text { Casa } \\
\text { alugada }\end{array}$ & $\mathrm{R} \$ 510,00$ \\
\hline
\end{tabular}

\section{Instrumentos}

O instrumento de pesquisa adotado foi a entrevista semiestruturada, realizada durante uma visita domiciliar. A entrevista representa um instrumento privilegiado de coleta de informações, pois sua principal contribuição é a possibilidade de revelar por meio da fala do sujeito condições estruturais, sistemas de valores, normas e símbolos "e ao mesmo tempo a magia de transmitir, através de um porta-voz, as representações de grupos determinados, em condições históricas, socioeconômicas e culturais específicas" (Minayo, 1993, p. 109-110). O roteiro para a entrevista com as famílias abordou os seguintes tópicos: 1 informações sobre as relações entre seus membros; história familiar; 2 - informações sobre a medida socioeducativa de internação; como a famillia lida com a internação do adolescente; como a família participou e participa do processo de internação do adolescente; Psico-USF, Bragança Paulista, v. 18, n. 2, p. 277-288, maio/agosto 2013 quem visita o adolescente; as atividades que o adolescente realiza na internação; significação da internação para a família; 3 - informações sobre a medida socioeducativa aplicada anteriormente; qual foi a medida socioeducativa que o filho cumpriu antes $\mathrm{da}$ internação; como era realizado o acompanhamento do filho nessa medida socioeducativa; qual a importância dessa medida socioeducativa na vida do filho e na vida da família; como a medida socioeducativa ajudou a família e o adolescente; 4 - informações sobre as perspectivas de futuro; como vai ser a vida depois que o adolescente sair da internação.

\section{Procedimentos}

A exploração do campo da pesquisa iniciou-se no Núcleo de Profissionalização da instituição, onde tivemos contato com os adolescentes. A partir de então, suas famílias foram contatadas e convidadas a 
participar da pesquisa. As entrevistas foram realizadas durante visitas domiciliares. É válido mencionar que a visita domiciliar para realização da entrevista com os responsáveis foi imprescindível, tendo em vista que o momento em que as famílias frequentam o CIAP é destinado para visitar os adolescentes, e entrevistá-las nesse momento diminuiria o pouco tempo que têm para ficar com seus filhos. Além disso, ir à casa das familias dos adolescentes permitiu conhecer melhor o contexto social em que estão inseridos; seus bairros, suas casas, a vizinhança, enfim, suas vidas extramuros à internação. As famílias foram entrevistadas no início do ano de 2011.

\section{Análise dos dados}

Para análise e interpretação dos dados, foi utilizada a técnica da análise de conteúdo, com a observação para as sugestões e críticas apresentadas por Minayo (1993). Desse modo, a análise dos dados contempla três passos principais, quais sejam: 1) ordenação dos dados; 2) classificação dos dados e construção das categorias de análise e 3) análise final, ou seja, a interpretação dos resultados da pesquisa a partir da fundamentação teórica adotada e de uma vinculação estratégica com a realidade.

\section{Cuidados éticos}

O trabalho realizado obteve autorização das instituições envolvidas, quais sejam: Vara da Infância e da Juventude do DF e CIAP. Ademais, todos os participantes foram esclarecidos em relação ao objetivo da pesquisa e os responsáveis assinaram o Termo de Consentimento Livre e Esclarecido. A pesquisa também foi aprovada pelo Comitê de Ética em Pesquisa do Instituto de Humanas da Universidade de Brasília em 16 de dezembro de 2010.

\section{Resultados e Discussão}

\section{Conbecendo as famílias}

Alan reside com sua mãe, Sra. Leda, e sua irmã mais nova, Aline (12 anos). Possui mais dois irmãos que não moram com eles, ambos com passagem pelo Sistema de Justiça, assim como seu genitor, acusado de matar a primeira esposa. A relação familiar é bastante conflituosa e Alan vivenciou muitas agressões do pai em relação à mãe. A Sra. Leda nos contou que uma vez Alan atirou contra a mão de seu genitor para protegê-la das ameaças de morte feitas pelo ex-marido. Nas palavras dela:

Ele [o ex-marido] me perseguia muito. Queria me matar. Queria matar esses meus meninos mais velhos ai e uma vez. o Alan atirou nele também por coisa das perseguições dele com a gente. O Alan falava: "Atirei mesmo. Eu ia era matar ele, para ele deixar de ser covarde e não sei o que, e aí está vingado o que ele fer. com a senhora". Só que assim... Eu até esqueço. É tanta coisa... Ai eles brigaram. O Felipe fez isso com ele e pronto.

Já Breno reside com seus pais, D. Silvia e Sr. José, uma irmã (Bruna, 22 anos) e um irmão (Bruno, 23 anos), sendo que este último cometeu o mesmo ato infracional que Breno, ou seja, porte de arma. Segundo relatos de Bruna, ela e os irmãos nunca presenciaram algum tipo de violência física entre os pais, porém nessa família observa-se a existência da negligência emocional. $\mathrm{Na}$ entrevista, os filhos se queixaram de falta de carinho, de afeto e de diálogo. Alegaram que, materialmente, os pais não lhes deixam faltar nada, mesmo com toda a simplicidade em que vivem, mas emocionalmente falta muita coisa.

A familia de Carlos é composta por sua mãe, Sra. Maria, a irmã (Carla, 23 anos), que já foi atendida na delegacia da criança e do adolescente por tráfico de drogas, e duas sobrinhas. O pai mora em outro estado e só viu o filho quando ainda era pequeno. Sra. Maria contou que ele era muito violento e com medo de morrer ou perder os filhos, fugiu para Brasília com as crianças, quando Carlos ainda tinha cerca de três anos de idade. A mãe de Carlos sempre trabalhou em casa de família e, muitas vezes, tinha de dormir na casa dos patrões, deixando os seus filhos sozinhos:

[...] ai eu tive que trabalhar. Eu dormia no serviço. Ai nós não tínhamos mais aquele contato, assim, aquela coisa de mãe protetora não tinha mais, que eu tinha que trabalhar para botar as coisas dentro de casa, pagar aluguel, porque eu saí de lá e não tinha nada, entendeu? Então eu queria construir uma vida.

Nota-se que em todas as famílias há histórico de envolvimento com o crime por parte de seus integrantes, sejam irmãos e/ou parentes mais distantes. Também é percebida a existência de violência, seja ela física ou emocional. Além do mais, as famílias entrevistadas são de baixa renda, residem em locais de maior vulnerabilidade social, conhecidos por serem violentos (as periferias urbanas), sendo que apenas a familia de Alan possui casa própria. Todas as mães são domésticas e, na família de Breno, único caso em que os pais residem juntos, o pai trabalha como pedreiro. As famílias vivem em contexto de pobreza, os genitores exercem profissões pouco valorizadas socialmente e a violência compõe suas histórias de vida. Esses aspectos compõem um contexto desfavorecido para esses adolescentes (Sales, 2007). 
"É dificil, mas en prefiro ele lá do que aqui, aprontando"

Essa foi a resposta de uma das famílias entrevistadas quando questionada sobre $\mathrm{O}$ envolvimento de seu filho com atos infracionais e como o fato de o filho estar em regime de restrição da liberdade afeta o sistema familiar. No geral, o cometimento do ato infracional é explicado pelas famílias como resultado da falta de orientação e presença dos pais, assim como o frágil diálogo entre eles e os filhos e a presença de más companhias. Nas palavras das famílias:

Familia Alan:

Sei lá. O Alan é assim: ele começou a usar essas coisas quando tinha uns 13 anos. De 13 para 14 anos. Ai foi roubar, aprontar, mas o pai dele ainda vivia dentro de casa [...] o pai dele também deu uns exemplos muito ruins. A gente só vivia brigando dentro de casa. Ai eu não sei se foi por causa da bagunça que ele via dentro de casa ou até porque ele se sentiu assim, solto. Mas não, porque ele comecou a aprontar com o pai mesmo dentro de casa. Ai não sei. Ele ia assim, nessa idade queria muito usar coisa que não tinha. Aí ele começou a ir roubar e a ser violento, igual ele foi assim, na rua. Mas ele só foi violento com o pai mesmo, com outras pessoas não. Nunca bateu em mim. O negócio dele é roubar mesmo. Aí eu não sei se é precisão ou o que é.

Família Breno: (genitora)

É como se... O problema eu acho que foi a falta de diálogo. O que en penso, assim. Não abriu os olhos. Foi deixando, deixando...

(irmã) A mãe trabalhava demais para não deixar faltar comida. Ele (Breno) sempre falava com a minha mãe. Ele chegava... Ele é o mais carinhoso também. Assim, ele é o mais apegado assim, com a minha mãe também. Tentava se aproximar da minha mãe, mas a minha mãe e meu pai nunca... Sabe... Nunca deu espaço para ele. Ele tentou se aproximar, mas não deu. Ele foi fez o que? Ele foi pra rua caşar amigo, né?

Familia Carlos:

[...] en sei que en tinha que trabalhar, tinha que me preocupar com o trabalho e não faltar as coisas pra eles. Não sei se esse foi meu erro. Não sei. Que eu queria que eles não passassem fome, en queria que eles tivessem um lugar pra dormir, tivessem um teto. Eu me preocupava nisso. Eu não chegava a imaginar de um dia o Carlos ia se envolver com essas coisas. Aí assim: quando en chegava dentro de casa no sábado, que en chegava duas horas, estava tudo tranquilo. Ninguém me falava... Assim, falava que ele estava saindo de noite, mas não falava assim, sempre.

Duas, das três famílias entrevistadas, são chefiadas por mulheres que precisaram deixar suas casas e filhos para garantir o essencial: comida, moradia, enfim, uma existência mínima. Mas ao optarem por seus empregos, quem vai cuidar de seus filhos? Quem vai orientá-los, auxiliá-los nas tarefas escolares, organizar a rotina do dia a dia? A resposta parece ser a rua, os vizinhos, o tráfico de drogas e o mundo. Nessa perspectiva, Sales (2007) evidencia, a partir de indicadores econômicos e de acesso a bens e serviços, que a família atravessa uma crise enquanto instituição no cenário mundial, mas que são os segmentos mais pauperizados da sociedade que sofrem com os impactos socioeconômicos.

Por conseguinte, no caso das mulheres chefes de familia, pertencentes às classes mais pauperizadas $\mathrm{e}$ com baixo índice de escolaridade, muitos são os obstáculos existentes para sua inserção no mercado de trabalho regular, como, por exemplo, a exigência de participação em tempo integral que, somada às quase nulas contrapartidas do Estado e dos patrões em oferecer suporte aos cuidados com seus filhos, obrigam as famílias a fazer escolhas que refletem intensamente sobre a não educação das crianças, sendo a educação entendida num contexto amplo, inclusive no aspecto dos valores morais e éticos (Sales, 2007). Também Minuchin (1982) faz essa análise da situação da família num contexto de grandes mudanças na sociedade, relatando que a família "tem assumido ou renunciado a funções de proteção e socialização de seus membros em resposta às necessidades da cultura" (p. 52) e, portanto, a família está abrindo mão da socialização das crianças cada vez mais cedo, não tendo a sociedade ainda desenvolvida "fontes extrafamiliares adequadas de socialização e apoio" (p. 53).

Os adolescentes em conflito com a lei são, sobretudo, resultado da conjuntura política, cultural, social e econômica na qual se encontra a nossa sociedade. Enquanto crianças e adolescentes que necessitam da atenção do Estado para garantir seus direitos básicos, como educação, saúde, assistência social, esses adolescentes e suas respectivas famílias esbarram na oferta mínima e inadequada dessas políticas sociais e, portanto, não conseguem superar as barreiras existentes, permanecendo à margem da sociedade, (in)visíveis, relegados socialmente. $\mathrm{O}$ conflito com a lei é um grito de socorro, uma forma de existência social, de se tornar visível.

Retomando a questão dos reflexos do conflito com a lei no sistema familiar, questiona-se como será para essas famílias lidar com a internação de seus filhos. As familias apontam a internação de seus filhos como algo difícil, pois, para algumas, o filho era a "alegria da casa, querido por todos"; para outras, o filho significava proteção contra as ameaças do ex-marido. Em suma, todas alegam que a internação gerou um vazio na família, mas com o qual elas foram se acostumando aos poucos. Sobre o "vazio" deixado pelos filhos, cabe aqui ponderar a respeito dos papéis 
que eles desempenham em suas famílias. Em uma das famílias entrevistadas, encontra-se a situação do filho que atira contra a mão do pai como forma de proteger a mãe de suas ameaças. Nessa mesma família, a mãe diz que sente muita falta do filho "[...] porque mesmo ele saindo para as ruas e tudo, ele ficava dentro de casa, era a minha companhia. Às vezes, quando o pai dele vinha aí caçar briga, ele estava perto para me defender".

Nessa fala, percebe-se a figura do filho parental que, conforme Penso e Sudbrack (2004), são adolescentes que desempenham diferentes papéis, ao lado da mãe, ao longo do Ciclo de Vida Familiar, ocupando espaços vazios da relação conjugal, mantendo-se numa relação de rivalidade e/ou de afastamento do pai. Assim sendo, "o desempenho e o investimento nesses papéis dificultam a identificação com seu pai e, também, o movimento de separaçãoindividuação desse adolescente de sua família, complicando o seu processo de construção identitária" (p. 36).

Esse filho parental é excluído do subsistema fraterno e elevado ao subsistema parental, assumindo prematuramente uma responsabilidade emocional considerável, que resulta na aproximação do adolescente em relação à mãe, com um gradual distanciamento do pai, sendo que esse distanciamento pode ocorrer quando o adolescente percebe que a mãe sofre na relação com o pai, como é o caso relatado pela mãe do adolescente Alan; é um exemplo que denuncia claramente a sua triangulação em relação aos pais, sendo denominado de defensor da mãe contra as agressões do pai (Penso \& Sudbrack, 2004). Para essas autoras, uma das maneiras que o adolescente que vive essa situação encontra para lidar com a angústia sentida e criar possibilidades de separação e de liberação desse lugar de filho parentalizado é a busca por outros contextos de construção identitária, nos quais se destaca o uso de drogas, que o leva, quase que simultaneamente, ao envolvimento com atos infracionais. $\mathrm{O}$ conceito de filho parental é importante ponto de compreensão da dinâmica familiar nas situações de envolvimento com drogas e ato infracional.

Assim, o uso de drogas e o cometimento de atos infracionais passam a ser analisados como um sintoma de toda a familia, sendo encarado como uma forma de lidar com os conflitos, mais do que um problema em si mesmo. A função desse sintoma é conduzir uma mensagem que denuncia falhas do sistema familiar e social, ao mesmo tempo em que indica a necessidade de mudança no seu funcionamento (Bulaccio, 1992).

$\mathrm{Na}$ mesma linha de pensamento, Krohn, Hall e Lizotte (2009) apontam em seu estudo que os adolescentes que vivem em familias que experimentam transições são mais propensos a cometer atos de delinquência e uso de drogas com maior frequência que os adolescentes que vivem em famílias que vivenciam poucas transições. Para os autores, entre as possíveis consequências das transições familiares que podem levar a comportamentos problemáticos estão as mudanças no bem-estar econômico da família, as tensões entre os membros da familia, o estresse que resulta de mudanças na organização familiar e os problemas relacionados a essas mudanças, assim como problemas no âmbito escolar.

Sobre as visitações à unidade de internação, mesmo com a saudade e o fato de terem que se deslocar semanalmente para a unidade de internação e passarem por situações que consideram constrangedoras, como diz Dona Silvia: "ah, só de tirar a roupa, já é uma bumilhação. Aquele pessoal olhando as comidas, ficar cortando as bananas... Tudo ali é humilhante", o sistema familiar vai se reorganizando $e$ as famílias se acostumam com seus filhos presos porque acreditam que lá eles estão protegidos dos perigos que o mundo oferece, evidenciando, assim, o que elas esperam da medida socioeducativa de internação, ou seja, o que não conseguiram fazer em relação à proteção de seus filhos.

\section{A significação das medidas socioeducativas para as familias}

Para as famílias entrevistadas, a internação está associada à ideia de proteção para os adolescentes e de tranquilidade para elas, no sentido de saberem que lá seus filhos estão protegidos dos perigos do mundo exterior. Também é vista pelas famílias como a única medida socioeducativa capaz de provocar reflexão aos adolescentes, no sentido de dar valor à liberdade. $\mathrm{Ou}$ seja, só restringindo a liberdade é que eles param para pensar.

Família Alan:

No fundo eu acho que é até bom, porque do jeito que o Alan estava aí, meu irmão, nossa. Se ele não estivesse ido para lá, eu não sei nem o que tinha acontecido, porque ele estava muito sem controle, sabe? Estava aprontando demais. Uma vez atrás da outra. Aí, para mim está sendo bom, porque ele está sossegado lá, está evitando muita coisa. E eu também estou um pouco mais tranquila. Para mim significa que en quero... Assim, que ele saia de lá bem. Está significando assim, que en eston tranquila. Porque se ele não estivesse internado, estava muito ruim com ele aí na rua aprontando. (grifo nosso)

Família Breno:

Muito dificil mesmo ver ele... Por mais que ele errou, entendeu? É muito dificil para nós. Muito mesmo. É. Amadurecimento, assim. Porque assim: as duas vezes que ele apronton, que ele ficon os 45 dias, en acho que 
ele não levou muito a sério. Igual ele estava lá no semi, né? Ai ele não cumpriu o semi direito, né? Aí eu acho que esse aí deu para ele... Ele agora está amadurecendo. Ele está vendo que a liberdade é bem mais importante, né? [...] Minha mãe quer dizer que antigamente ele passava os 45 dias, ele pensava: "ah, 'de menor', não dá nada mesmo. Vou aprontar". Mas agora ele está bem. Já tem sete meses e ele nem tem previsão de quando ele vai sair. Ele pode ficar até três anos. Agora sim está caindo a ficha dele, né? Ele está achando que ele vai aprontar e não dá nada. Não, né?. (grifo nosso)

Familia Carlos:

O Tiago agora já pensa diferente, entendeu? [...] Ele fala: "é. Se en tivesse feito o que a senhora me pediu, o que a senhora me falava, en não estava aqui, né, mãe?" Eu falo: "É." "Mas eu não escutei a senhora". Então boje ele já pensa diferente. Então se ele não tivesse lá, ele estava naquela: não, eu... Que nem ele falava, que ele era "de menor", que ele só ficava 45 dias e podia voltar pra casa. Era isso... Que ele achava que podia fazer, fazer e não ficava preso. Agora, pra ele, ele já sabe. Ele já pensa melhor. Tem importância pra mim, porque lá o Tiago não está aprontando. Aqui fora, o Tiago... Eu, como mãe, eu tinha medo de uma hora chegar uma notícia: "mataram seu filho, seu filho está morto", entendeu? Quantas mortes já teve aqui e en fui ver, e en falava assim: "Meu Deus! Não me deixa passar por isso, de ver aquele corpo no chão". Uns criticando, que era bandido, que não prestava, que era um vagabundo, entendeu? Então eu não quero passar por isso. Eu quero que men filho mude de vida. (grifo nosso)

Outra consideração que fazem sobre a internação é que esta seria a única medida socioeducativa capaz de mostrar aos adolescentes que eles podem ser punidos, mesmo "sendo de menor", como pode ser visualizado na seguinte fala: "já está mudando mais, que ele está vendo que 'de menor' tem punição sim". Percebe-se a confusão existente entre impunidade penal e inimputabilidade, que Volpi (2001) aponta como um dos mitos existentes em torno dos discursos proferidos pelo senso comum a respeito das medidas socioeducativas. Segundo esse mito, os adolescentes estariam mais propensos ao cometimento de atos infracionais porque a legislação aplicada a eles é muito branda em termos de punição. Percebe-se, nesse sentido, uma má compreensão dos conceitos de inimputabilidade penal e impunidade, ou seja, o adolescente pode ser inimputável do ponto de vista penal, mas isso não exclui o fato de que ele é responsabilizado pelo cometimento do ato infracional, tanto é que existem as medidas socioeducativas. A relevância desse mito para este trabalho reside justamente no fato de que o não-funcionamento adequado das medidas socioeducativas, em que pesem as medidas socioeducativas em meio aberto, contribui para repercussão dessa confusão conceitual.

As próprias famílias criticam as outras medidas socioeducativas, sejam elas as em meio aberto ou em meio fechado, no caso, a semiliberdade. Para as famílias de Alan e Breno, que cumpriram semiliberdade, os adolescentes tinham muita liberdade e ficavam muito ociosos. Um dos adolescentes nem chegou a estudar quando estava na semiliberdade, pois evadiu em menos de um mês. Sobre a questão da liberdade, uma fala chamou atenção: "Lá era muito liberal. Ele saía para comprar pão. Saía, ia para a esquina. Era como se ele estivesse em casa. Ele saía. Fez foi piorar." Ou seja, tem-se a noção de que a medida só tem efeito se priva o adolescente de quase toda a liberdade.

É importante ressaltar que os dois adolescentes que cumpriram a semiliberdade evadiram da medida e as familias não comunicaram as autoridades responsáveis, apenas aconselharam seus filhos, o que não adiantou em nada, eles continuaram evadidos. No caso da família de Alan, sua mãe falou o seguinte sobre a situação do filho na semiliberdade: “[...] ele não respeitou foi nada e reclamava muito de lá, que era ruim, que estava longe e não sei o quê. Aí um dia que ele veio em casa, voltou e na outra semana ele não quis, não", ou seja, o filho não quis cumprir a medida e ela acatou.

Essa situação evidencia as contradições muitas vezes existentes entre regras familiares e regras sociais, em que a transgressão da regra familiar tem maior importância e impacto para a família que a transgressão da regra social, da lei, conforme expõe Segond (1992). Cabe aqui uma fala muito intrigante da Sra. Leda, mãe de Alan, quando fala sobre o momento em que descobriu que o filho estava cometendo furtos $\mathrm{e}$ roubos, em que ela não deixou claro que não era para o filho roubar, apenas disse para ele não levar "essas coisas" para casa:

Eu sei que ele andou chegando com umas coisas aí. Não chegava mais porque en brigava. Falei: "Alan, en não sei onde você está arrumando isso, mas eu não quero essas coisas aqui, não". Ai en acho que ele roubava pra lá. Não chegava... Aí parou de chegar aqui com as coisas. Por lá mesmo ele gastava para lá.

Para a família do adolescente Carlos, que cumpriu Liberdade Assistida (LA) e Prestação de Serviços à Comunidade (PSC), as medidas não surtiram efeito nem para família, nem para o adolescente. No caso da LA, era só assinar um papel mensalmente; a genitora nunca ia à unidade de execução por causa do trabalho e, à época, o adolescente não estudava, tampouco, fazia 
qualquer tipo de curso, só ia "assinar um papel" e conversar com a técnica. A familia nunca recebeu uma visita da equipe de execução da LA e nunca participou de nenhuma atividade. Para a genitora, a medida não valeu a pena:

Assim, pra ele ficar melhor? Não, porque eu não achei nada. Assim, que nem uma vez, en fiquei desempregada e eu fui lá no CDS, poxa, não me ajudaram em nada. A Cristiane era que ia com ele, aí eu não podia, porque você sabe: doméstica, tem que está ali... Não tem pra onde. Só que aí, na hora lá, eu não sei o que eles falavam pra ele, o que ele faria, não sei. Eu sei que sempre chegava um boletim pra assinar.

No caso da PSC, a genitora só foi no primeiro dia levar o filho para conhecer o local e apresentá-lo. Depois, o adolescente ia por conta própria, mas deixou de cumprir porque estava sendo ameaçado de morte e a genitora informou o fato à Vara da Infância, mas não teve retorno algum. Resumindo, as famílias não participavam de nenhuma atividade sistemática na execução das medidas socioeducativas mencionadas, em nenhuma delas os adolescentes fizeram curso profissionalizante e apenas Breno estudava quando no cumprimento dessas medidas socioeducativas. E, para as familias, as medidas socioeducativas que os adolescentes receberam antes $\mathrm{da}$ internação não serviram para nada. Para essas familias, a internação é considerada a única medida capaz de "dar conta" desses adolescentes e que, logo, causa nas famílias a sensação de que lá eles estão protegidos.

Sobre essa comparação entre a medida socioeducativa de internação e as demais medidas, Conceição (2010) relata que é fato que a maioria dos adolescentes que cometem algum ato infracional grave em que cabe a aplicação da medida socioeducativa de internação acumula um histórico de transgressões consideradas mais brandas, o que nos leva a deduzir que "as medidas antes aplicadas não foram eficazes, pois não preveniram a reincidência" (p. 92). Por conseguinte, a internação é vista como a solução, uma vez que as demais medidas socioeducativas fracassaram em seu propósito socioeducativo. Contudo:

não se pode responsabilizar o Estatuto por esses fracassos, pois, na realidade, essas propostas não estão sendo aplicadas de acordo com o que está previsto. A responsabilidade não é outra senão da própria sociedade que fracasson em viabilizar os mecanismos estabelecidos, mas que insiste na prática estereotipada de travestir sua culpa e condenar os próprios adolescentes quando transgridem a lei (Conceição, 2010, p. 93).

Já com relação ao caráter protetor que é atribuído à medida socioeducativa de internação e cujas famílias compartilham, Conceição (2010) elucida que "embora possa proteger o adolescente de si mesmo, no caso dos ameaçados de morte, o confinamento é uma contenção para vida" (p. 91), pois denuncia a inoperância das políticas sociais que visam garantir direitos e proteção, inoperância esta que reflete nas estatísticas de violência contra os jovens. De fato, se o objetivo da internação é trabalhar o adolescente para retornar ao "convívio social" dentro das regras socialmente aceitas, o que vemos é que, ao egressarem do confinamento, torna-se muito mais difícil ser aceito socialmente; os adolescentes continuam "temidos" e, agora, mais do que nunca, marcados, estigmatizados.

\section{O envolvimento das famílias na execução das medidas socioeducativas e perspectivas de futuro}

Falou-se sucintamente no tópico anterior sobre a participação das famílias nas medidas socioeducativas anteriores à internação, ou seja, de que não participavam ativamente na execução das medidas impostas a seus filhos, pois suas presenças não foram exigidas. $O$ entendimento das famílias quanto à participação na execução da medida socioeducativa de internação pode ser resumido em uma única ação: visitas semanais. Religiosamente, aos domingos, as mães dos adolescentes vão até o CIAP para visitarem seus filhos. Tentam levar aquilo que eles mais gostam e que é permitido: "Desde a primeira vez, sempre que ele vai preso eu visito ele. Eu tendo as coisas para levar ou não, eu vou. Levo alguma coisa quando tem. Quando não tem, eu não levo" (família Alan). O único dia da semana em que não precisam trabalhar (pois trabalham aos sábados) é destinado para os filhos detidos.

Mas além de visitar e conversar, aconselhar os seus filhos, o que mais elas fazem na instituição? As famílias de Breno e Carlos mencionaram a existência de reuniões com os pais, para explicar o que acontece lá dentro, apresentar os profissionais, falar das dificuldades da unidade, etc. Mas informam que nem sempre podem participar dessas reuniões ou simplesmente não se atentam às datas, "[...] assim, teve um dia que teve uma atividade lá, mas só que assim: eu pego os papéis, não lei. Aí, quando eu vou ver, já tinha..." (família do Breno). Ademais, na maioria das vezes, as familias nem sabem dizer direito quais são as atividades que os filhos desenvolvem dentro da unidade de internação. Ou seja, apesar de sempre visitarem os filhos, sabem pouco do que ocorre lá dentro e não se sentem no direito de cobrar e exigir do Estado uma melhor execução da medida. Muitas vezes entregam seus filhos e pronto. O envolvimento delas na execução da internação é muito superficial.

Familia Alan: Nunca me falaram nada do colégio. Eu sempre pergunto para o Felipe, e ele diz que está estudando. Só fala que 
está estudando. Deve ser aula normal, assim, de escola. Não é, não? Ou é oficina?

Familia Breno: ele joga bola três vežes na semana, parece. Deixa en ver: a tarde é na escola, né? Aí ele faz. esse curso. Tem um curso lá. Agora, eu não sei do que é. Ele falou lá.

Familia Carlos: Não. Eu não sei. Eu pergunto e ele só fala que está estudando. Eu falo: "O que você está fazendo?" "Estou estudando".

Mas o que está por trás dessa participação superficial, desse pouco envolvimento? Encontramos em Demo (2008) uma das possíveis respostas: pobreza política. Para o autor, a pobreza não é sinônima apenas da ausência de bens materiais, pois mera carência não gera, necessariamente, pobreza. Ou seja, "pobreza é carência politizada, no sentido de a carência servir para o favorecimento de alguns em detrimento de muitos" (Demo, 2008, p. 1) e tem como pano de fundo o confronto político entre uns poucos que se apropriam de bens e poder e muitos que ficam de fora, mas "ficar de fora não é termo correto, porque, sendo pobreza parte integrante desta sociedade, os pobres estão dialeticamente incluídos, embora na margem, na periferia, tal qual numa unidade de contrários" (Demo, 2008 , p. 2). Assim, a noção de pobreza política sugere que a carência de cidadania possivelmente seja a dimensão mais grave nos pobres, porque essa carência impede que se tornem protagonistas de sua própria emancipação. Ou seja, ser pobre politicamente significa não se reconhecer enquanto sujeito de direito. É por isso que essas famílias não sabem cobrar do Estado, neste caso, da unidade de internação, cursos melhores, uma escola de qualidade, mais atividades e menos tempo ocioso. São pobres, ignorantes em saber exigir do Estado e da sociedade, enquanto cidadãs, que os seus filhos sejam respeitados e tenham seus direitos assegurados. Castro e Guareschi, 2007; Sales, 2007; Volpi, 2001 são exemplos de autores que concordam que essas condições socioeconômicas são estruturantes de como esses sujeitos se colocam diante de suas prerrogativas.

A crítica de Pedro Demo (2008) em torno das políticas sociais coloca justamente que a resposta dada pelo Estado ao enfrentar as problemáticas sociais não passa de políticas pobres para o pobre. Ou seja,

é correto partir do pobre, se o quisermos como sujeito participativo, mas é contraditório deixá-lo na pobreza. Parte-se da pobreza para sair dela [...] na verdade, o sistema não teme um pobre com fome, mas teme um pobre que sabe pensar. (p. 9)

Outra reflexão importante a respeito $\mathrm{da}$ participação das famílias na execução das medidas socioeducativas dos filhos pode ser visualizada no trabalho de Peterson-Badali e Broeking (2009), que ao analisarem a legislação canadense destinada aos jovens em conflito com a lei, a Youth Criminal Justice Act (YCJA), identificaram que a legislação contém pouca discussão dos princípios ou pressupostos que regem o envolvimento dos pais e não fornece orientações específicas sobre como os pais têm de cumprir os seus papéis. Desse modo, cabe aos diversos funcionários envolvidos na execução da lei interpretar as intenções da legislação com respeito ao lugar dos pais e de envolvê-los, de acordo com essa interpretação. Muitas vezes, a falta de uma orientação adequada aos pais em relação ao seu papel na execução das medidas socioeducativas dos filhos pode gerar uma compreensão equivocada a respeito do papel da instituição, dando espaço para mais e mais desencontros. Essa brecha também pode ser observada no ECA.

Quanto ao futuro de seus filhos, as familias mencionaram o desejo de que eles trabalhem, estudem e consigam uma vida digna e, consecutivamente, a questão do trabalho sempre vem em primeiro lugar, evidenciando que, para essas famílias, o trabalho é visto como meio de se alcançar uma vida digna e de se tornarem responsáveis por si próprios: "Toda mãe pensa o melhor para os filhos. Trabalhar, fazer curso, tentar fazer uma faculdade. Eu estou falando: ver se vocês trabalham e vão cassar o rumo de vocês. A gente pensa o melhor, né?"(familia do Breno). No caso das familias dos adolescentes Alan e Breno, as falas das genitoras só mostram desejos, sem algo mais concreto. No caso da familia do Carlos, já se percebe um empenho maior da família para auxiliar o adolescente nessa "mudança de vida" como, por exemplo, mudar de localidade, pois ele tem muitas rixas na cidade onde reside e a genitora acredita que se eles ficarem na cidade o adolescente não terá chances para promover essa mudança. Inclusive, menciona o apoio da equipe técnica do CIAP, quanto à orientação, para a mudança de localidade, uma vez que a família reside de aluguel.

\section{Considerações finais}

Este estudo mostrou que, para as familias, as medidas em meio aberto ou fechado, no caso, a semiliberdade, são significadas por elas como algo sem importância em suas vidas e na de seus filhos. $\mathrm{Na}$ verdade, essa "falta de importância" está relacionada ao insucesso dessas medidas socioeducativas em relação ao papel de ressocialização de seus filhos. Entretanto, já a medida socioeducativa de internação é significada pelas familias como a única capaz de promover a proteção de seus filhos e de provocar alguma mudança em suas vidas, pois o peso de perder a liberdade, para essas famílias consegue fazer com que os adolescentes reflitam sobre suas práticas. Muito além de garantir 
proteção e provocar reflexão, a medida socioeducativa de internação "dá conta" do que as familias não conseguiram, ou seja, consegue afastá-los de seus grupos, de suas práticas infracionais. Porém, priva-os de sua liberdade e isso não necessariamente gera uma mudança de comportamento nos adolescentes.

Com base nas falas dos sujeitos entrevistados, comparando-se a medida socioeducativa de internação com as demais medidas, sejam as em meio aberto e a semiliberdade, a internação é a única medida que consegue garantir minimamente o que o ECA preconiza, ou seja, escola, profissionalização, lazer, saúde, acompanhamento psicossocial, etc. Ou seja, parece que há um investimento muito maior na internação do que nas demais medidas, que são consideradas as que possuem maiores chances de "transformar" o adolescente e suas condutas, mas que, ao serem pouco valorizadas, não produzem os resultados almejados. Assim, há uma conduta por parte do Estado que condiz com a perspectiva penalpolicial e que vai, inclusive, contra as próprias normativas, tal como o ECA, pois, segundo este, a internação é medida aplicada em último caso. No entanto, quando não se investe nas demais medidas socioeducativas, principalmente nas medidas em meio aberto, os adolescentes vão parar na internação, seja pelo não-cumprimento $\mathrm{da}$ medida anteriormente aplicada, ou pela reincidência na prática do ato infracional ou seja por cometimento de ato infracional mais grave.

Finalmente, neste texto enfocamos a significação das medidas para os adolescentes e familiares. Contudo, seria importante a realização de uma investigação voltada aos profissionais que atuam junto aos adolescentes, em todas as áreas, ou seja, na equipe técnica, escola, saúde, segurança, enfim, em todos os ambientes que compõem a unidade de internação. Afinal, os profissionais que atuam junto aos adolescentes e suas famílias representam a presença do Estado e, desse modo, suas intervenções devem estar em consonância com as normativas legais e com a proposta da Doutrina da Proteção Integral.

\section{Referências}

Bulaccio, B. (1992). Familia e a clínica da drogadição. Psicologia Teoria e Pesquisa, 8, suplemento, 459-468.

Brasil (1988). Constituição Federal da República

Castro, A. L. S. \& Guareschi, P. A. (2007). Adolescentes autores de atos infracionais: processos de exclusão e formas de subjetivação. Psicologia Politica, 7(13), 43-60.

Conceição, M. I. G. (2010). A clínica do adolescente em meio fechado: olhares sobre o contexto. Em:
M. M. Marra \& L. F. Costa (Org.). Temas da clínica do adolescente e da família (pp. 87-103). São Paulo: Ágora.

Demo, P. (2008). Pobreza política. Obtido em 28 abril, 2011. Do site $<$ http://pedrodemo.sites.uol.com.br/textos/ppro ma.html>.

Estatuto da Criança e do Adolescente (ECA) (1990).

Esteves de Vasconcellos, M. J. (2002). Pensamento Sistêmico: o novo paradigma da ciência. Campinas: Papirus.

Fishman, H. C.(1988). Tratando adolescentes com problemas: uma abordagem da terapia familiar. Porto Alegre: Artes Médicas.

Garcia, M. B. (1999). Um sistema de garantia de direitos - fundamentação (A). Em Garcia, M. B. (1999). Sistema de Garantia de Direitos (pp. 93-110). Recife: CENDHEC.

Krohn, M. D., Hall, G. P. \& Lizotte, A. J. (2009). Family Transitions and Later Delinquency and Drug Use. Journal of Youth and Adolescence. 38, 466480.

Machado, M. T. (2003). Apanhado histórico-filosófico das concepções que orientam o direito da criança e do adolescente (pp. 25-54). Em A proteção constitucional de crianças $e$ adolescentes $e$ os direitos bumanos. São Paulo: Manole.

Minayo, M. C. S. (1993). O desafio do conhecimento: pesquisa qualitativa em saúde ( $2^{\mathrm{a}}$ ed.). São Paulo: Hucitec.

Minuchin, S. (1982). Familias: funcionamento e tratamento. Porto Alegre: Artes Médicas.

Penso, M. A. \& Sudbrack, M. F. O. (2004). Envolvimento em atos infracionais e com drogas como possibilidades para lidar com o papel de filho parental. Psicologia USP, 15(3), 29-54.

Peterson-Badali, M. \& Broeking, J. (2009) Parents' Involvement in the Youth Justice System: A View from the Trenches. Canadian Journal of Criminology and Criminal Justice, 51(2), 255-270.

Sales, M. A. (2007). (In)visibilidade perversa: adolescentes infratores como metáfora da violência. São Paulo: Cortez.

Segond, P. (1992). Família e transgressão. Psicologia: Teoria e Pesquisa, 8(suplemento), 433-445.

Veronese, J. R. P. \& Luz, V. P. (coord.). (2006). Direito da criança e do adolescente. vol. 5. Florianópolis: $\mathrm{OAB} / \mathrm{SC}$ Editora.

Volpi, M. (org). (2001). Sem liberdade, sem direitos: a privação de liberdade na percepção do adolescente. São Paulo: Cortez.

Wanderlino, N., Neto. (1999). A Convenção Internacional sobre o Direito da Criança e a Busca do Equilibrio entre Proteção e Responsabilização. Em Sistema de Garantia de 
Direitos: um caminho para a Proteção Integral. Recife: Centro Dom Helder Câmara de Estudos e Ação Social CENDHEC.

Recebido em 06/09/2012 Reformulado em $05 / 03 / 2013$

Aprovado em 14/05/2013

Nota das autoras:

Este texto é parte dos resultados da Dissertação de Mestrado "Da liberdade à privação: a significação de medidas socioeducativas para adolescentes e familiares", da primeira autora orientada pela segunda autora, e defendida em julho de 2011 perante o Programa de Pós-Graduação em Psicologia Clínica e Cultura - UnB.

Sobre as autoras

Luana Alves de Souza é mestre em Psicologia Clínica pela Universidade de Brasilia e assistente Social da Secretaria de Estado de Desenvolvimento Social e Transferência de Renda do Governo do Distrito Federal.

Liana Fortunato Costa é psicóloga, terapeuta familiar, psicodramatista e doutora em Psicologia Clínica pela Universidade de São Paulo. Atua no programa de Pós-Graduação em Psicologia Clínica e Cultura da Universidade de Brasilia.

Contato com as autoras

Luana Alves de Souza

Rua Bernardo Sayão, Quadra 154, Casa 02 - CEP 73330-055 - Planaltina-DF, Brasil.

E-mail: luana.alvessouza@gmail.com 